\title{
Spor Yapan Bireylerin Yeni Besin Korkusu ve Ortoreksiya Nervoza Eğilimleri ile Beslenme Durumları Arasındaki İlişkinin Belirlenmesi
}

\section{The Determination of the Relationship between Food Neophobia and Orthorexia Nervosa Tendencies and Nutritional Status of Individuals Who Engage in Sports}

\author{
Işınsu Baysal ${ }^{1}$, Gül Kızıltan²
}

Geliş tarihi/Received: 16.06 .2020 • Kabul tarihi/Accepted: 26.12.2020

\section{ÖZET}

Amaç: Bu çalışma, spor yapan bireylerin yeni besin korkusu ve ortoreksiya nervoza eğilimleri ile beslenme durumları arasındaki ilişkiyi belirlemek amacıyla yapılmıştır.

Bireyler ve Yöntem: Çalışma, Aralık 2019-Nisan 2020 tarihleri arasında Ankara'da bulunan bir spor merkezine en az 3 aydır devam eden, 18-64 yaş arası 107 gönüllü birey (53 erkek, 54 kadın) üzerinde yürütülmüştür. Katılımcıların kişisel özellikleri, beslenme alışkanlıkları, egzersiz davranışları bir anket aracılığıyla sorgulanmış ve antropometrik ölçümleri alınmıştır. Katılımcıların yeni besinlerden kaçınma veya yeni besinleri deneme eğilimlerini belirlemek için Yeni Besin Korkusu Ölçeği kullanılmıştır. Ölçek puanı $<\overline{\mathrm{X}} \pm$ SS olan bireyler neofilik, $\overline{\mathrm{X}}_{ \pm} \mathrm{SS}$ nötr, $>\overline{\mathrm{X}} \pm \mathrm{SS}$ neofobik olarak değerlendirilmiştir. Katılımcıların sağlıklı beslenme takıntılarının belirlenmesinde ORTO-11 ölçeği kullanılmış olup 23 puan ve altı ortorektik eğilim olarak değerlendirilmiştir. Katılımcıların besin tüketim durumları ise Besin Tüketim Sıklık formu kullanılarak saptanmıştır.

Bulgular: Cinsiyete göre yeni besin korkusu ve ORTO-11 ölçek puanları açısından istatistiksel olarak önemli bir fark bulunmamıştır ( $p>0.05)$. Yeni besin korkusu arttıkça yapraklı sebze/ot tüketimi azalmaktadır $(\mathrm{p}<0.05)$. Ortorektik eğilimi olan bireylerde, ortorektik eğilimi olmayan bireylere göre sebze tüketiminin daha fazla, et ürünü/sakatat tüketiminin daha az olduğu saptanmıştır ( $\mathrm{p}<0.05)$. Yeni besin korkusu zayıflama amacıyla, haftada 1-2 kez spor yapan bireylerde daha yüksek iken; ortorektik eğilimin vücut geliştirme ve sağlı̆̆ını koruma amacıyla, sıklıkla haftada 5 kez ve üzeri spor yapan bireylerde daha yüksek olduğu görülmüştür (p>0.05). On iki ay ve daha uzun süredir spor yapanların ORTO-11 puanı, daha az süredir spor yapanlara göre daha düşüktür $(\mathrm{p}<0.05)$.

Sonuç: Bu çalışma, yeni besin korkusu ve ortoreksiya nervoza arasında bir ilişki olabileceğini ve egzersiz davranışlarını etkileyebileceğini göstermiştir. Bu bulguları doğrulamak için daha fazla araştırma yapılması gerekmektedir.

Anahtar kelimeler: Spor, ortoreksiya nervoza, yeni besin korkusu

\section{ABSTRACT}

Aim: This study was conducted to determine the relationship between food neophobia and orthorexia nervosa tendencies and nutritional status of individuals who engage in sports.

1. İletişim/Correspondence: Başkent Üniversitesi, Sağlık Bilimleri Fakültesi, Beslenme ve Diyetetik Bölümü, Ankara, Türkiye

E-posta: isinsubaysal@hotmail.com • ๑ https://orcid.org/0000-0003-0534-1755

Çalışma, aynı başlıklı yüksek lisans tezinden üretilmiştir.
2. Başkent Üniversitesi, Sağlık Bilimleri Fakültesi, Beslenme ve Diyetetik Bölümü, Ankara, Türkiye • ํ https://orcid.org/0000-0001-5012-5838 
Subjects and Method: The study was conducted on 107 volunteers (53 males, 54 females) between the ages of 18-64 who have been attending a sports center in Ankara for at least 3 months between December 2019-April 2020. Participants' personal characteristics, nutritional habits, exercise behaviours were assessed using a questionnaire and their anthropometric measurements were taken. Food Neophobia Scale was used to determine participants' tendency to avoid or try new foods. Individuals with a scale score of $<$ mean \pm SD was evaluated as neophilic, mean \pm SD as neutral and $>$ mean \pm SD as neophobic. ORTO-11 scale was used to determine healthy eating obsessions of participants and 23 points and below were evaluated as orthorexic tendency. Food Frequency Questionnaire form was used to determine the nutritional status of participants.

Results: No statistically significant differences were found between males and females on the Food Neophobia Scale and ORTO-11 Scale scores ( $p>0.05$ ). It was observed that the consumption of leafy vegetables/herbs decreased as the level of food neophobia increased $(p<0.05)$. It was determined that the consumption of vegetables was higher, and the consumption of meat and offal products was lower in orthorexic individuals than non-orthorexic individuals $(\mathrm{p}<0.05)$. Food neophobia was seemed higher in individuals who exercise 1-2 times a week for weight loss, and orthorexic tendency was seemed higher in individuals who exercise 5 times a week or more for bodybuilding and health protection ( $p>0.05$ ). It was found that ORTO-11 scores of individuals who engaged in sports for at least a year was lower than who engaged in sports for lesser time $(p<0.05)$.

Conclusion: This study showed that there may be a relationship between food neophobia and orthorexia nervosa and these may affect exercise behaviours. More research is needed to confirm these findings.

Keywords: Sports, orthorexia nervosa, food neophobia

\section{GíRiş}

Düzenli olarak egzersiz yapmak, sağlığı korumanın ve geliştirmenin yanı sıra bireylerin sahip olmak istedikleri fiziksel görünümlerine ulaşabilmelerini sağlamaktadır. Ancak beden üzerine aşırı yoğunlaşma ve beslenme şekli ile aşırı ilgilenme birçok yeme bozukluğuna zemin hazırlamaktadır (1). Yeme alışkanlığında meydana gelen değişiklikler ise bireylerin beden algisinın daha da bozulmasina yol açmaktadır (2). Bu döngünün kırılabilmesi ve koruyucu önlemlerin alınabilmesi açısından, düzenli olarak spor yapan bireylerde yeni besin korkusu ve ortoreksiya nervoza gibi var olan tanı kriterlerine uymayan beslenme ve yeme bozuklukları örüntülerinin de dikkate alınması gerekmektedir.

Yeni besin korkusu (food neophobia), yeni/ bilinmeyen besinleri tüketmekten kaçınma eğilimi olarak tanımlanmaktadır (3). Yapılan çalışmalarda, daha önceden denenmemiş besinlerin "potansiyel olarak toksik/zehirli” gibi düşünülmesi, bu kaçınma eğiliminin altında yatan sebep olarakgösterilmektedir. Reddetme davranışlarının çoğunlukla balık, meyve, sebze, yapraklı sebzelere/otlara (maydanoz, fesleğen vb.) karşı olduğu rapor edilmiştir (4-6). Reddedilen sağlıklı besinlerin yerini genellikle enerji yoğunluğu yüksek, işlenmiş besinler almakta; bu durum ise enerji alımını ve obezite riskini artırmaktadır (5).

Ortoreksiya nervoza, takıntılı bir şekilde sağlıklı beslenme davranışını ifade etmektedir (7). Ortorektik bireyler yiyeceğin miktarı ile değil, kalitesi ile ilgilenmektedirler. Besinlerin üretim, işleme ve paketleme aşamalarının yanı sıra hazırlama ve pişirme yöntemlerine de çok dikkat etmektedirler (8). Kanserojen madde, katkı maddesi, boya veya hormon içeren ürünlerin; yüksek miktarda tuz, şeker ve sağlıksız yağ içeren besinlerin tüketiminden kaçınan ortorektik bireyler, genellikle çiğ sebze ve meyve tüketmektedir (9). Sadece "saf ve sağlıklı" besinlerin tüketilmesine yönelik yapılan bu sıkı diyete bağlılık, birçok besin ögesi alımını ortadan kaldırarak vücut ağırlığı kaybına ve önemli sağlık sorunlarına neden olabilmektedir (8).

Yapılan çalışmalar, yeni besin korkusu ve ortoreksiya eğilimi olan bireylerin besin tüketimindeki seçiciliğinin iki zıt uçta olduğunu göstermektedir (311). Yeterli ve dengeli beslenmeyi karşılayamayan beslenme davranışlarının özellikle daha kaliteli 
bir yaşama sahip olmak için spor yapan bireylerde taranması, risk gruplarının aydınlatılması açısından önemlidir. $\mathrm{Bu}$ çalışmanın amacı, spor yapan bireylerin yeni besin korkusu ve ortoreksiya nervoza eğilimleri ile beslenme durumları arasındaki ilişkiyi belirlemektir.

\section{BİREYLER VE YÖNTEM}

\section{Araştırmanın Yeri, Zamanı ve Örneklemi}

$\mathrm{Bu}$ çalışma Ankara'da, bir spor merkezine vücut geliştirme, zayıflama ve sağlıklı yaşam amacıyla en az 3 aydır devam eden, 18-64 yaş arası 107 bireyin (53 erkek, 54 kadın) gönüllü olarak katılımı ile gerçekleştirilmiştir. Çalışma için Başkent Üniversitesi Klinik Araştırmalar Etik Kurulu'ndan onay (KA19/349 nolu ve 06.11.2019 tarihli) alınmıştır. Bireyler çalışma hakkında bilgilendirilmiş ve gönüllü onam formunu okuyup imzalamıştır.

\section{Veri Toplama Aracı}

Çalışmaya katılan bireylere demografik özelliklerini, genel sağlık durumlarını, beslenme alışkanlıklarını, egzersiz davranışlarını ve antropometrik ölçümlerini belirlemek amacıyla anket formu uygulanmıştır. Bireylerin antropometrik ölçümleri araştırmacı tarafindan, mezura ve TANITA 418-MA Biyoelektrik Empedans Cihazı kullanılarak alınmıştır.

Sağlıklı beslenme konusunda bireylerin takıntısını belirlemek amacıyla ORTO-11 ölçeği uygulanmıştır. Bratman (12) tarafindan hazırlanan 10 soruluk ölçek, Donini et al. (13) tarafindan geliştirilmiş ve ORTO-15 halini almıştır. Ölçeğin Türkçe geçerlik ve güvenirliği Arusoğlu et al. (7) tarafından yapılmış ve Türkçe'de ORTO-11 şeklinde kullanımına karar verilmiştir. On bir maddeden oluşan likert tipi ölçekte düşük puanlar ortoreksiya nervoza riskinin arttığını göstermektedir. Ölçeğin değerlendirilmesi için kesim noktası elde etme yöntemi kullanılmıştır. Çalışmanın kesim noktası \%25'lik dilimde 23 puan olarak belirlenmiş olup 23 puan ve altı ortorektik eğilim olarak değerlendirilmiştir (7).
Bireylerin yeni besinlerden kaçınma veya yeni besinleri deneme eğilimini değerlendirmede Yeni Besin Korkusu Ölçeği (Food Neophobia Scale, FNS) kullanılmıştır. Pliner ve Hobden (3) tarafindan geliştirilmiş olan ölçeğin Türkçe geçerlik ve güvenirliği Uçar (14) tarafından yapılmıştır. On maddeden oluşan likert tipi ölçekten alınan yüksek puanlar yeni besin korkusunu, düşük puanlar ise yeni besinleri denemekten hoşlanmayı göstermektedir $(3,14)$. Yeni besin korkusu ölçek puanı $<\overline{\mathrm{X}} \pm$ SS olan bireyler yeni besinlerden hoşlanan/neofilik, $\overline{\mathrm{X}} \pm \mathrm{SS}$ nötr, $>\overline{\mathrm{X}} \pm \mathrm{SS}$ yeni besin korkusu yüksek olan bireyler/neofobik olarak değerlendirilmiştir.

Besin Tüketim Sıklık formundan yararlanılarak bireylerin besin tüketim durumları saptanmıştır. Literatürde yer alan bilgiler ışığında (3-11), yeni besin korkusu ve ortoreksiya nervoza eğilimi olan bireylerin tüketme ve kaçınma davranışları gösterdikleri belirli besin grupları göz önüne alınmış ve Beslenme Bilgi Sistemleri Paket Programı (BeBiS, Versiyon 8.2) aracılığıyla günlük tüketilen ortalama miktarlar belirlenmiştir (15).

Anket formundaki sorular bireylere yüz yüze görüşme tekniği ile sorulmuştur.

\section{Verilerin İstatistiksel Analizi}

Çalışmadan elde edilen verilerin değerlendirilmesi ve tabloların oluşturulması amacıyla SPSS 22.0 İstatistik Paket Programından yararlanılmıştır. Ölçümle elde edilen nicel değişkenler ortalama $(\bar{X})$, standart sapma (SS), alt ve üst değerler ile, kategorik değişkenler ise sayı (S) ve yüzde (\%) olarak ifade edilmiştir. Bağımsız iki grubun ortalamaları; normal dağılım gösterenlerde Student t testi, normal dağılım göstermeyenlerde Mann-Whitney U testi kullanılarak karşılaştırılmıştır. İkiden fazla grubun ortalamalarının karşılaştırılmasında ise; normal dağılım gösterenlerde tek yönlü varyans analizi (Oneway ANOVA) yapılmış ve farklılığın hangi gruplardan kaynaklandığının belirlenmesinde TUKEY HSD testi kullanılmıştır. Normalliğin sağlanmadığı durumda Kruskal Wallis testi ile gruplar arasındaki farklılık 
analiz edilmiş ve fark olması durumunda post-hoc analizi Bonferroni düzeltmeli Mann-Whitney U testi ile yapılmıştır. Kategorik değişkenlerin analizinde ki-kare testi kullanılmıştır. Araştırmadan elde edilen bulgular \%95 güven aralığında, \%5 anlamlılık düzeyinde değerlendirilmiştir.

\section{BULGULAR}

Yeni besin korkusu ölçek puanlarına bakıldığında; erkeklerin ölçek puanı ortalama $36.4 \pm 9.48$ iken, kadınların $37.2 \pm 8.90$ bulunmuştur. Yeni besin korkusu düzeyine göre neofilik, nötr ve neofobik olarak değerlendirilen bireylerin oranı erkeklerde sırasıyla \%11.3, \%73.6 ve \%15.1 iken, kadınlarda sirasıyla \%16.7, \%66.7 ve \%16.7 olarak belirlenmiştir. ORTO-11 puanları incelendiğinde; erkeklerin ORTO-11 puanı ortalama $26.5 \pm 5.19$ iken, kadın bireylerin 25.6 \pm 4.38 olarak bulunmuştur. Erkeklerin \%32.1’i, kadınların ise \%27.8'i ortorektik eğilim göstermektedir. Cinsiyete göre yeni besin korkusu ve ORTO-11 ölçek puanları açısından istatistiksel olarak önemli bir fark bulunmamıştır ( $p>0.05$ ) (Tablo 1).

Tablo 2'de bireylerin yeni besin korkusu ve ortoreksiya nervoza durumlarına göre günlük tükettikleri besin/ besin gruplarının ortalama değerleri verilmiştir. Bireylerin yeni besin korkusu düzeyleri (neofiliknötr-neofobik) arttıkça sebze, yapraklı sebze/ot, meyve, balık ve deniz ürünleri tüketiminin azaldığı; et ürünü/sakatat, kek/pasta/bisküvi ve şekerleme/ çikolata/dondurma tüketiminin arttığı görülmüştür. Yeni besin korkusu düzeyine göre yapraklı sebze/

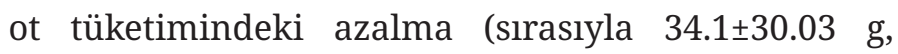
$23.9 \pm 18.75 \mathrm{~g}, 11.8 \pm 10.71 \mathrm{~g}$ ) istatistiksel olarak önemli bulunmuştur $(\mathrm{p}<0.05)$. Farklılı̆̆ın, neofobik bireyler ile nötr bireyler arasındaki farklılıktan kaynaklandığı belirlenmiştir $(\mathrm{p}<0.017)$.

Ortorektik eğilimi olan bireylerde, ortorektik eğilimi olmayan bireylere göre sebze, yapraklı sebze/ot, meyve, balık ve deniz ürünleri tüketiminin daha fazla; et ürünü/sakatat, kek/pasta/bisküvi, şekerleme/ çikolata/dondurma ve beyaz ekmek tüketiminin daha az olduğu saptanmıştır. Ortorektik eğilimi olan ve olmayan bireylerde sebze tüketimi sirasiyla $114.6 \pm 105.98 \mathrm{~g}$ ve $65.8 \pm 51.48 \mathrm{~g}$; et ürünü/sakatat tüketimi $0.6 \pm 1.26 \mathrm{~g}$ ve $2.8 \pm 6.25 \mathrm{~g}$ olarak belirlenmiş ve bu fark istatistiksel olarak önemli bulunmuştur $(\mathrm{p}<0.05)$ (Tablo 2).

Tablo 3'te bireylerin egzersiz davranışlarına göre yeni besin korkusu ve ORTO-11 ölçek puanları verilmiştir. Buna göre; yeni besin korkusu zayıflama amacıyla, haftada 1-2 kez spor yapan bireylerde daha yüksek iken ( $p>0.05$ ); ortorektik eğilim vücut geliştirme ve sağlığını koruma amacıyla, haftada 5 kez ve üzeri spor yapan bireylerde daha yüksek bulunmuştur ( $p>0.05$ ). Bunun yanı sira 12 ay ve daha uzun süredir spor yapan bireylerin ortorektik eğilimleri, daha az süredir spor yapan bireylere göre daha yüksek bulunmuştur ( $p<0.05)$. Farklılığın, 12 ay ve daha uzun süredir spor yapan gruptan kaynaklandığı belirlenmiştir.

Tablo 1. Bireylerin yeni besin korkusu ve ORTO-11 ölçek puanı ortalamaları ve dağılımı

\begin{tabular}{|c|c|c|c|c|c|c|c|c|}
\hline \multirow[t]{2}{*}{ Ölçek } & & \multicolumn{2}{|c|}{$\begin{array}{l}\text { Erkek } \\
\text { (n:53) }\end{array}$} & \multicolumn{2}{|c|}{$\begin{array}{l}\text { Kadın } \\
\text { (n:54) }\end{array}$} & \multicolumn{2}{|c|}{$\begin{array}{l}\text { Toplam } \\
\text { (n:107) }\end{array}$} & \multirow[t]{2}{*}{$\mathbf{p}$} \\
\hline & & $\mathbf{S}$ & $\%$ & $\mathbf{S}$ & $\%$ & $\mathbf{S}$ & $\%$ & \\
\hline \multirow{5}{*}{ 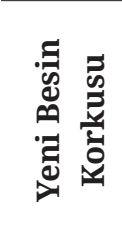 } & Puan ortalaması $(\overline{\mathrm{X}} \pm \mathrm{SS})$ & \multicolumn{2}{|c|}{$36.4 \pm 9.48$} & \multicolumn{2}{|c|}{$37.2 \pm 8.90$} & \multicolumn{2}{|c|}{$36.8 \pm 9.16$} & \multirow[t]{2}{*}{0.650} \\
\hline & Puan dağılımı & & & & & & & \\
\hline & Neofilik & 6 & 11.3 & 9 & 16.7 & 15 & 14.0 & \\
\hline & Nötr & 39 & 73.6 & 36 & 66.7 & 75 & 70.1 & 0.681 \\
\hline & Neofobik & 8 & 15.1 & 9 & 16.7 & 17 & 15.9 & \\
\hline \multirow{4}{*}{ 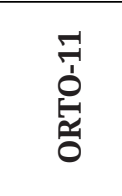 } & Puan ortalaması $(\overline{\mathrm{X}} \pm \mathrm{SS})$ & \multicolumn{2}{|c|}{$26.5 \pm 5.19$} & \multicolumn{2}{|c|}{$25.6 \pm 4.38$} & \multirow{2}{*}{\multicolumn{2}{|c|}{$26.0 \pm 4.79$}} & \multirow[t]{2}{*}{0.377} \\
\hline & Puan dağılımı & & & & & & & \\
\hline & Ortorektik eğilimi olan & 17 & 32.1 & 15 & 27.8 & 32 & 29.9 & \multirow{2}{*}{0.627} \\
\hline & Ortorektik eğilimi olmayan & 36 & 67.9 & 39 & 72.2 & 75 & 70.1 & \\
\hline
\end{tabular}


Tablo 2. Bireylerin yeni besin korkusu ve ortoreksiya nervoza durumlarına göre günlük tükettikleri besin/besin gruplarının ortalama değerleri (g) $\left(\overline{\mathrm{X}}_{ \pm} \mathrm{SS}\right)$

\begin{tabular}{|c|c|c|c|c|c|c|c|}
\hline \multirow[b]{2}{*}{ Besin Grupları } & \multicolumn{4}{|c|}{ Yeni Besin Korkusu (g) $\left(\overline{\mathrm{X}}_{ \pm} \mathrm{SS}\right)$} & \multicolumn{3}{|c|}{ Ortoreksiya Nervoza $(\mathrm{g})\left(\overline{\mathrm{X}}_{ \pm} \mathrm{SS}\right)$} \\
\hline & $\begin{array}{c}\text { Neofilik } \\
\text { (n:15) }\end{array}$ & Nötr (n:75) & $\begin{array}{c}\text { Neofobik } \\
\text { (n:17) }\end{array}$ & $\mathbf{p}^{1}$ & $\begin{array}{c}\text { Ortorektik } \\
\text { (n:32) }\end{array}$ & $\begin{array}{c}\text { Ortorektik } \\
\text { olmayan } \\
\text { (n:75) }\end{array}$ & $\mathbf{p}^{2}$ \\
\hline Sebzeler & $87.9 \pm 46.64$ & $87.7 \pm 83.61$ & $41.4 \pm 34.58$ & 0.064 & $114.6 \pm 105.98$ & $65.8 \pm 51.48$ & $0.003^{*}$ \\
\hline Yapraklı sebzeler ve otlar & $34.1 \pm 30.03$ & $23.9 \pm 18.75$ & $11.8 \pm 10.71$ & $0.015^{*}$ & $25.1 \pm 21.04$ & $22.7 \pm 20.35$ & 0.663 \\
\hline Meyveler & $156.7 \pm 122.74$ & $147.5 \pm 103.89$ & $84.5 \pm 65.39$ & 0.058 & $157.1 \pm 115.47$ & $130.9 \pm 97.95$ & 0.371 \\
\hline Balık ve deniz ürünleri & $33.2 \pm 47.74$ & $22.5 \pm 21.10$ & $20.2 \pm 18.99$ & 0.890 & $31.5 \pm 38.43$ & $20.3 \pm 17.90$ & 0.197 \\
\hline Et ürünleri ve sakatatlar & $1.0 \pm 3.09$ & $2.3 \pm 6.11$ & $2.5 \pm 2.89$ & 0.051 & $0.6 \pm 1.26$ & $2.8 \pm 6.25$ & $0.006^{*}$ \\
\hline Beyaz ekmek & $30.6 \pm 52.67$ & $43.8 \pm 2.82$ & $35.1 \pm 59.33$ & 0.890 & $22.6 \pm 46.00$ & $48.2 \pm 74.43$ & 0.113 \\
\hline Kek, pasta ve bisküvi & $15.9 \pm 21.43$ & $14.6 \pm 22.84$ & $20.6 \pm 25.86$ & 0.418 & $14.1 \pm 23.51$ & $16.5 \pm 22.95$ & 0.385 \\
\hline Şekerleme, çikolata ve dondurma & $8.5 \pm 11.50$ & $9.7 \pm 12.19$ & $14.1 \pm 9.85$ & 0.315 & $7.9 \pm 7.86$ & $11.2 \pm 13.04$ & 0.341 \\
\hline
\end{tabular}

Tablo 3. Bireylerin egzersiz davranışlarına göre yeni besin korkusu ve ORTO-11 ölçek puanları

\begin{tabular}{|c|c|c|c|c|c|c|}
\hline & \multicolumn{3}{|c|}{ Yeni Besin Korkusu } & \multicolumn{3}{|c|}{ Ortoreksiya Nervoza } \\
\hline & $\overline{\mathrm{X}} \pm \mathrm{SS}$ & Alt-Üst & $\mathbf{p}^{1}$ & $\overline{\mathrm{X}} \pm \mathrm{SS}$ & Alt-Üst & $\mathbf{p}^{2}$ \\
\hline \multicolumn{7}{|c|}{ Spor yapma süresi } \\
\hline 3-6 ay & $38.1 \pm 9.90$ & $18-69$ & & $26.8 \pm 4.50$ & $18-35$ & \\
\hline $6-12$ ay & $38.5 \pm 8.43$ & $11-50$ & 0.077 & $27.9 \pm 4.09$ & $19-33$ & $0.002^{*}$ \\
\hline 12 ay ve üzeri & $34.1 \pm 8.42$ & $15-50$ & & $24.0 \pm 4.88$ & $15-33$ & \\
\hline \multicolumn{7}{|c|}{ Haftalık spor yapma sıklığı } \\
\hline $1-2 \mathrm{kez}$ & $37.7 \pm 8.66$ & $11-54$ & & $26.5 \pm 4.17$ & $17-33$ & \\
\hline $3-4 \mathrm{kez}$ & $36.9 \pm 9.02$ & $18-69$ & 0.682 & $26.3 \pm 4.74$ & $16-35$ & 0.187 \\
\hline $5 \mathrm{kez}$ ve üzeri & $35.0 \pm 10.82$ & $15-50$ & & $23.9 \pm 5.63$ & $15-33$ & \\
\hline \multicolumn{7}{|c|}{ Spor yapma amacı } \\
\hline Vücut geliştirme & $34.5 \pm 9.97$ & $15-49$ & & $25.5 \pm 5.30$ & $15-33$ & \\
\hline Sağlıklı yaşam & $36.1 \pm 7.73$ & $11-50$ & 0.133 & $25.8 \pm 5.32$ & $16-35$ & 0.549 \\
\hline Zayıflama & $39.0 \pm 9.75$ & $19-69$ & & $26.7 \pm 3.79$ & $19-35$ & \\
\hline
\end{tabular}

${ }^{*} p<0.05$

$p^{1}$ : Yeni besin korkusu ölçek puanı ortalamaları arasındaki fark, $p^{2}$ : Orto-11 puanı ortalamaları arasındaki fark

\section{TARTIŞMA}

\section{Bireylerin Yeni Besin Korkularının Değerlendirilmesi}

Canlılar hayatta kalmak ve üremek için anne sütünden farklı besin kaynaklarına yönelip tüketmeye istekli olmaktadır. Öte yandan, yeni besin kaynaklarının toksin içermesi gibi zararlı etkilerinin olabileceği düşüncesi canlıları yeni besinlerden uzak durmaya itmektedir. Yeni besin korkusu, canlıların besleyici özelliklere sahip olan besini tükettikten sonra güvenilir olduğunu öğrenmesiyle azalmaktadır (4). Yeni besinlerin tanındığı 2-6 yaş arası çocukluk çağında yeni besin korkusunun en yüksek seviyede olduğu ileri sürülmektedir (16). Bununla birlikte, yetişkin bireylerle yapılan çalışmalarda, yeni besin korkusunun daha düşük diyet kalitesi ve daha yüksek beden kütle indeksi ile ilişkili olduğu bulunmuştur (5). 
Cinsiyetin yeni besin korkusuna etkisinin değerlendirildiği bir çalışmada, yeni besin korkusu erkeklerde kadınlara göre daha yüksek bulunmuş (6), başka bir çalışmada ise yeni besin korkusunun kadın bireylerde daha yüksek olduğu ifade edilmiştir (17). Bu çalışmada ise, kadınların yeni besin korkusu ölçek puanı ortalaması erkeklere göre daha yüksek bulunsa da bu farkın istatistiksel olarak önemli olmadığı saptanmıştır ( $p>0.05$ ) (Tablo 1).

Yeni besin korkusu ile besin/besin gruplarının tüketim ilişkisi incelendiğinde; 8-16 yaş aralığındaki çocuk ve adölesanlarla yapılan bir çalışmada, yeni besin korkusu yüksek olanların daha fazla şekerli besin; daha az meyve, sebze ve balık tükettikleri görülmüştür (10). Başka bir çalışmada, 21-99 yaş arası yetişkin ve yaşlı bireylerden yeni besin korkusu yüksek olanların daha az miktarda balık, kümes hayvanları, sebze, yapraklı sebze/ ot tükettikleri bulunmuştur (6). Bu çalışmada da benzer sonuçlar alınmıştır; yeni besin korkusu düzeyi arttıkça sebze, yapraklı sebze/ot, meyve, balık ve deniz ürünleri tüketiminin azaldığı; et ürünü/sakatat, kek/pasta/ bisküvi ve şekerleme/çikolata/dondurma tüketiminin arttığı görülmüştür. Yeni besin korkusu düzeyine göre yapraklı sebze/ot tüketimindeki azalmanın önemli düzeyde olduğu belirlenmiştir $(p<0.05)$ (Tablo 2). Laureati el al. (11) yaptığı çalışmada, bireylerin yeni besin korkusu arttıkça keskin/acı tada sahip olan sebzeleri beğeni düzeylerinin azaldığı gösterilmiştir $(p<0.05)$. Mevcut çalışmada, yeni besin korkusuna göre sebze tüketimindeki önemli farkın yapraklı sebze/ot grubunda görülmesi (Tablo 2), bu besinlerin diğer sebzelere göre daha keskin/acı bir tada sahip olmasından kaynaklanıyor olabilir.

Artan yeni besin korkusu ile birlikte diyet kalitesinin azaldığı, reddedilen sağlıklı besinlerin yerini genellikle enerji yoğunluğu yüksek ve işlenmiş besinlerin aldığı görülmektedir. Bu durum ise enerji alımını ve obezite riskini artırmaktadır (5). Beslenme ve yeme bozukluğu olan bireyler egzersizi bir kaçış aracı olarak görebilmekte, egzersiz ile yeme davranışını telafi etmeyi veya vücut ağırlığını azaltmayı hedeflemektedirler (18). Yapılan bu çalışmada da, yeni besin korkusu yüksek olan bireylerin zayıflama amacıyla spor yaptıkları görülmüştür ( $p>0.05$ ) (Tablo 3).

Yeni besin korkusu ve kişilik boyutları arasındaki ilişkiyi inceleyen az sayıdaki araştırmalarda, deneyime açıklık ve dışa dönüklük ile yeni besin korkusu arasında negatif yönde güçlü bir ilişki olduğu rapor edilmiştir $(19,20)$. Mevcut çalışmada, yeni besin korkusu yüksek bireylerin zayıflama amacıyla spor yapmalarına rağmen haftalık spor yapma sıklıklarının haftada 1-2 kez ( $\mathrm{p}>0.05$ ) olması (Tablo 3), deneyime açık ve dışa dönük yapıda olmadıkları için spor merkezine sık gitmemelerinden kaynaklanabilir.

\section{Bireylerin Ortorektik Eğilimlerinin Değerlendirilmesi}

Arusoğlu et al. (7), sağlıklı yemenin pozitif davranış olarak varsayılmasinın, ortoreksiya nervoza prevalansı ile ilgili istatistiklere ulaşılmasını zorlaştırdığını belirtmektedir. Varga et al. (21) ise ortoreksiya yaygınlık oranını genel popülasyon için \%6.9 olarak bildirmiş ve yüksek riskli gruplar (sağlık profesyonelleri, sanatçllar) için bu oranın \%35 ile \%57.8 arasında değiştiğini ifade etmiştir.

Cinsiyetin ortoreksiya nervoza eğilimine etkisinin değerlendirildiği bazı çalışmalarda $(22,23)$ ortoreksiya nervoza eğiliminin kadın bireylerde erkeklere göre daha fazla olduğu belirtilmiştir. Donini et al. (13), erkek bireylerin ortorektik eğilim oranının kadınlara göre daha yüksek olduğunu saptamıştır. Örneklemini spor yapan bireylerin oluşturduğu çalışmalarda da genel olarak, erkeklerin ortoreksiya nervoza eğilimlerinin kadınlara göre daha fazla olduğu rapor edilmiştir (1,24). Bu çalışmada, erkeklerin \%32.1'inin, kadınların \%27.8'inin ortorektik eğilim gösterdiği saptanmış ancak cinsiyetler arası fark istatistiksel olarak önemli bulunmamıştır ( $p>0.05$ ) (Tablo 1).

Ortorektik bireyler saf olmayan ve sağlıksız besinlerin tüketiminden kaçınmaktadır (9). Bu çalışmada yer alan ortorektik bireylerde, ortorektik olmayanlara 
göre sebze, yapraklı sebze/ot, meyve, balık ve deniz ürünleri tüketiminin daha fazla; et ürünü/ sakatat, kek/pasta/bisküvi ve şekerleme/çikolata/ dondurma tüketiminin daha az olduğu görülmüştür. Ortorektik eğilimi olan ve ortorektik eğilimi olmayan bireylerin sebze tüketimleri ve et ürünü/sakatat tüketimleri arasındaki fark istatistiksel olarak önemli bulunmuştur $(\mathrm{p}<0.05)$ (Tablo 2).

$\mathrm{Bu}$ çalışmada, vücut geliştirme ve sağlığını koruma amacıyla, sıklıkla haftada 5 kez ve üzeri spor yapan bireylerde ortorektik eğilimin daha yüksek olduğu görülmüştür (p>0.05) (Tablo 3). Yapılan araştırmalarda mevcut çalışmayı destekler nitelikte; daha sık egzersiz yapan bireylerde ortorektik eğilimin daha fazla görüldüğü rapor edilmiştir $(24,25)$. Ortoreksiya nervoza bireylerde ancak uzun dönem görülüyorsa tanımlanabilmektedir (1). Bu çalışmada da, 12 ay ve daha uzun süredir spor yapanların ortorektik eğilimlerinin, daha az süredir spor yapanlara göre yüksek bulunması $(\mathrm{p}<0.05)$ (Tablo 3) beklenen bir sonuçtur.

$\mathrm{Bu}$ çalışma, spor yapan bireylerde yeni besin korkusu ve ortoreksiya nervoza ilişkisini ilk kez ortaya koymuştur. Çalışmanın, beslenmeyle ilişkili davranış değişikliklerinin aydınlatılması ve farkındalık oluşturulması amacıyla geliştirilen araştırmalara yol göstermesi beklenmektedir.

Çalışmaya katılan birey sayısının az olması, çalışmanın kısıtlılığı olarak görülmektedir. Bununla birlikte bireyler, anket yanıtlarını etkileyebilecek psikopatoloji, obsesif özellikler veya vejetaryenlik gibi belirli yemek seçimleri veya kalıpları açısından değerlendirilmemiştir. Bu değerlendirmeler olmadan mevcut çalışmanın, yeni besin korkusu ve ortoreksiya nervoza eğilimlerini net bir şekilde ortaya koymakta yetersiz kalmış olabileceği düşünülmektedir. Bu bakımdan, daha geniş çaplı araştırmaların yapılması gerekmektedir.

Çıkar çatışması - Conflict of interest: Yazarlar çılkar çatışması olmadığını beyan ederler. - The authors declare that they have no conflict of interest.

\section{KAYNAKLAR}

1. Dalmaz M. Spor salonunda spor yapanlarda ortoreksiya nervoza belirtilerinin incelenmesi [Yüksek Lisans Tezi]. İstanbul Arel Üniversitesi Sosyal Bilimler Enstitüsü, İstanbul; 2014.

2. Oruçlular Y. Vücut algısının aracı rolü üzerinden özerk-ilişkisel benlik özellikleri ve yeme tutumu ilişkisi [Yüksek Lisans Tezi]. Hacettepe Üniversitesi Sosyal Bilimler Enstitüsü, Ankara; 2013.

3. Pliner P, Hobden K. Development of a scale to measure the trait of food neophobia in humans. Appetite 1992;19:105-20.

4. Rioux C, Picard D, Lafraire J. Food rejection and the development of food categorization in young children. Cogn Dev. 2016;40:163-77.

5. Knaapila AJ, Sandell MA, Vaarno J, Hoppu U, Puolimatka T, Kaljonen A, et al. Food neophobia associates with lower dietary quality and higher BMI in Finnish adults. Public Health Nutr. 2015;18(12):2161-71.

6. Siegrist M, Hartmann C, Keller C. Antecedents of food neophobia and its association with eating behavior and food choices. Food Qual Prefer. 2013;30(2):293-8.

7. Arusoğlu G, Kabakçı E, Köksal G, Merdol TK. Ortoreksiya nervoza ve Orto-11'in Türkçeye uyarlama çalışması. Turk Psikiyatri Derg. 2008;19(3):283-91.

8. Koven NS, Abry AW. The clinical basis of orthorexia nervosa: emerging perspectives. Neuropsychiatr Dis Treat. 2015;11:385-94.

9. Chaki B, Pal S, Bandyopadhyay A. Exploring scientific legitimacy of orthorexia nervosa: A newly emerging eating disorder. Journal of Human Sport and Exercise. 2013;8(4):1045-53.

10. Maiz E, Balluerka N. Nutritional status and Mediterranean diet quality among Spanish children and adolescents with food neophobia. Food Qual Prefer. 2016;52:133-42.

11. Laureati M, Spinelli S, Monteleone E, Dinnella C, Prescott J, Cattaneo C, et al. Associations between food neophobia and responsiveness to "warning" chemosensory sensations in food products in a large population sample. Food Qual Prefer. 2018;68:113-24.

12. Bratman S, Knight D. Health Food Junkies: Overcoming the Obsession with Healthful Eating. New York: Broadway Books, 2000.

13. Donini LM, Marsili D, Graziani MP, Imbriale M, Cannella C. Orthorexia nervosa: A preliminary study with a proposal for diagnosis and an attempt to measure the dimension of the phenomenon. Eat Weight Disord. 2004;9(2):151-7.

14. Uçar EM. Yetişkin bireylerde yeni besin korkusu ve diyet kalitesinin değerlendirilmesi [Yüksek Lisans 
Tezi]. Hacettepe Üniversitesi Sağllk Bilimleri Enstitüsü, Ankara; 2018.

15. Ebispro for Windows, Stuttgart, Germany; Turkish Version (BeBiS 8.2), Pasifik Elektirik Elektronik Ltd. Şti. (www.bebis.com.tr); Istanbul, 2019.

16. Dovey TM, Staples PA, Gibson EL, Halford JCG. Food neophobia and picky/fussy eating in children: A review. Appetite. 2008;50(2-3):181-93.

17. Demattè ML, Endrizzi I, Biasioli F, Corollaro ML, Pojer N, Zampini M, et al. Food neophobia and its relation with olfactory ability in common odour identification. Appetite. 2013;68:112-7.

18. American Dietetic Association. Position of the American Dietetic Association: Nutrition Intervention in the Treatment of Eating Disorders. J Am Diet Assoc. 2011;111:1236-41.

19. Knaapila A, Silventoinen K, Broms U, Rose RJ, Perola M, Kaprio J, et al. Food neophobia in young adults: Genetic architecture and relation to personality, pleasantness and use frequency of foods, and body mass index-A twin study. Behavior Genetics. 2011;41:512-21.
20. Nezlek JB, Forestell CA. Food neophobia and the Five Factor Model of personality. Food Qual Prefer. 2019;73:210-4.

21. Varga M, Dukay-Szabó S, Túry F, van Furth EF. Evidence and gaps in the literature on orthorexia nervosa. Eat Weight Disord. 2013;18:103-11.

22. Şanlıer N, Yassıbaş E, Bilici S, Şahin G, Çelik B. Does the rise in eating disorders lead to increasing risk of orthorexia nervosa? Correlations with gender, education, and body mass index. Ecol Food Nutr. 2016;55(3):266-78.

23. Tek NA, Ermumcu MŞK. Sağllk profesyonellerinde sağlıklı beslenme kaygısı: Ortoreksiya Nervoza (ON). Gazi Üniversitesi Sağlık Bilimleri Dergisi. 2016;1(2):5971.

24. Almeida C, Borba VV, Santos L. Orthorexia nervosa in a sample of Portuguese fitness participants. Eat Weight Disord. 2018;23(4):443-51.

25. Bona E, Szél Z, Kiss D, Gyarmathy VA. An unhealthy health behavior: analysis of orthorexic tendencies among Hungarian gym attendees. Eat Weight Disord. 2019;24:13-20. 